\title{
Public Perception of Data Visuals in Media Coverage During COVID-19 Pandemic: The Risk Perception Model Revisited
}

\author{
Dilek Melike Uluçay \\ Gizem Melek \\ Deniz Özyurda-Ergen \\ Yaşar University (Turkey)
}

The aim of this research is to examine the role that data visuals in media coverage play on the risk perception of the public in times of a pandemic. The article reports findings from an online survey of 191 adults regarding the trajectory of the risk perception model during COVID-19 pandemic in Turkey. We focused on eight statements clustered into three groups as indicators of the risk perception when the public came across with the data visuals: (1) the level of anxiety, fear and panic arousals, (2) the level of lacking credibility and trust and (3) the level of impression regarding fatality, irreversible effects and catastrophic consequences. For the survey, we selected 24 data visuals, which attracted the most interaction from Facebook and Twitter accounts of the seven most popular news outlets. We asked respondents to score eight items for each 24 data visuals of COVID-19 news reports. The results suggest that the respondents find the data presented in visuals credible and trustworthy and they agree that the visuals depict risk elements in many cases. Implications of the low and high levels of risk perception regarding data visuals on media for the risk communication theory are discussed.

Keywords: COVID-19, pandemic, risk perception, data visuals, survey.

A n outbreak of a new coronavirus (COVID-19) in Wuhan, China, which was first reported to the World Health Organization Country Office on 31 December 2019, became a public health emergency of international concern on 30 January 2020. Due to the rapid increase in the number of cases outside China, the virus affected a growing number of countries, and The World Health 
Organization announced COVID-19 outbreak a pandemic on 12 March 2020. Globally, the number of laboratory-confirmed COVID-19 cases is 2.954.222, and the number of deaths is 202.597 as of 29 April 2020 ("Coronavirus...", 2020). Turkey is in the first ten countries in the world with 117.589 reported cases and 3.081 reported deaths as of 29 April 2020 ("Türkiye'deki...", 2020).

Several studies have stated that pandemics do not only lead to medical and physical health problems but also mental and psychological problems, such as; stress, anxiety, fear and panic (Al-Rabiaah et al., 2020). Similar to previous pandemics, the new corona virus has caused strong negative emotions in the public, which resulted in distorted risk perception, decision readiness, deliberation, thinking, and information acquisition in a short while (Huang, 2020; DeSteno, 2020).

Media has an important role to provide information to the public in several different topics especially during crises like outbreaks (Wahlberg and Sjoberg, 2000). Moreover, print media, TV and radio spread information acquired from public health agencies and have a vivid impact on risk perception (Chew and Eysenbach, 2010). Today people receive a lot of information about the pandemic COVID-19 ranging from the latest data to the symptoms of the disease from the media. Social media is also crucial in terms of disseminating information in high-concern environments. Previous research illustrated that social media is one of the main channels to spread information about outbreaks and to share fear and concerns of the users (Guidry et al., 2020; Chew and Eysenbach, 2010). For instance, during the 2009 H1N1 (swine flu) outbreak Twitter was used frequently as the main source of information (Chew and Eysenbach, 2010).

On the other hand, data visualizations have been commonly used to transfer numerical health and risk information to the public and to clarify messages. Since quantitative information is generally complicated to perceive, visuals enable the receiver to comprehend and interpret the data accurately. Especially in risk environments, disseminating the correct messages in a short period of time is pivotal due to the fact that misinformation can disturb the public. Therefore, data visuals can be an efficient tool for risk communication strategies (Shin, 2016). Currently, the media frequently spread messages by using data visuals of the new coronavirus, COVID-19.

In this context, the aim of this study is to investigate how data visuals of COVID-19 shared on Twitter and Facebook accounts of news sources have an impact on the public's risk perception. For the purpose of the study, we will answer the following research question;

RQ: How do participants perceive data visuals of COVID-19 shared on Facebook and Twitter by the media in the realm of the three main constructs of Risk Perception Model?

Although the effect of data visuals regarding its relationship with persuasion has been studied before (see Shin, 2016; Pandey et al., 2014), the perception of the data visuals within the context of risk communication has not been investigated. Even though risk communication and risk perception have a rich literature, there is no study discussing the effect of data visuals in this process. Besides, the impact of COVID-19 pandemic on societies is still yet to unfold. Therefore, 
exploring the agents that might have any effect on the public's risk perception during a pandemic such as COVID-19 would be a contribution.

\section{OUTBREAKS IN MEDIA}

The World Health Organization (2010) defines pandemic as a newly occurring disease caused by viruses, and tends to spread worldwide. In order to acknowledge the distinctive properties of a pandemic, it is coherent to check into geographic extension, disease movement, attack rates and explosiveness, immunity, novelty, infectiousness, contagiousness and severity of the disease. These epidemiologic features are all in favour to distinct the new born diseases whether they are endemic, epidemic or pandemic (Morens, Folkers and Fauci, 2009).

This classification defining the pandemic is significant for the media to choose the necessary information before disseminating them to the public. In retrospect, there are several examples of outbreaks in the world that are helpful to comprehend the importance of the media interest in the subject. Excluding the black death plague which occurs in the 14th century, the late history of pandemic diseases is a 90 years long process. The timeline begins with Spanish Flu in 1918, The Avian disease in 1998, continues with SARS virus -from the coronavirus family - in 2003, and Swine Flu in 2009 (a different subset of H1N1, which caused the Spanish Flu). Recent epidemics, such as MERS virus first detected in 2012 and continued until 2015 which is a Middle East oriented viral respiratory disease that is caused by a coronavirus (Mers-CoV) and Ebola outbreak in 2014 had their places in media, raising awareness and also public anxiety as a result. Lastly, COVID-19 (caused by SARS-CoV-2 virus) as a pandemic, the world acknowledged and received widespread media coverage.

Media's representation of the disease plays an important role in forming the reactions and emotions of the society. Additionally, it creates an informative connection between health organizations and the society. The message given by the media directly influences the coping process. For example, during the Spanish Flu pandemic in 1918, the United States and European countries had different approaches in terms of their communication strategies. While the United States government and health officials decided to give lesser information in order to reduce panic, European countries determined a policy where they discuss the effects and precautions of the disease openly. The disease peaked twice in the United States and only once in European countries (Angeli, 2012: 210). This result shows that the representation of the disease had an effect on the reactions of the society which designates the severity of the pandemic. Furthermore, the period revealed there is a clear connection between the government's policy and the media representation of the pandemic diseases. Another significant issue on the media representation is that the load and the content of the information may affect people, and overloaded or missing data results in dangerous consequences. Because of the panic spread by the media during the avian influenza (H5N1) outbreak in 2005, people thought that they are in an immediate need of the vaccine and because of the scarcity created by the sold out vaccines, other 
people who are in need of the medication were not able to buy it (Falagas and Kiriaze, 2006). Similarly, in Portugal during the 2009 Swine Flu (H1N1) outbreak, overly informative and overconfident traditional media affected the situation in a drastic way by dragging the society to panic and anxiety (Lopes et al., 2012: 26).

The technological evolution through the years and the dependently generated concept of new media shifted the perception of the pandemic and the representation of it. Social media also has a strong impact on people's way of thinking, emotional processing and perception of the ongoing process of pandemic diseases. According to Szomszor, Kostkova, and Louis (2011), Twitter is heavily used and usually an effective tool for people to spread information about flu outbreaks, even if some popular information may be wrong. Another study uncovers that Twitter can be used to track information in order to identify the unseen effects caused by the pandemics (Lampos and Cristianini, 2010). In 2020's pandemic disease COVID-19 the change of the representation seems more clearer as a result of the convergence of the mass media with the new media. For instance, the decision of the mainstream media to spread the news about the pandemic in their social media accounts by using data graphics is a new feature of the pandemic coverage of the media.

\section{COVID-19 AND MEDIA}

To date, the virus spread to 6 continents, 210 countries, with 2,883,603 confirmed cases (World Health Organization, 2020). Different from other epidemic diseases and pandemics, COVID-19 virus could infect people asymptomatically. The researches show that transmitting of the virus between an asymptomatic or pre-symptomatic person to others is possible which means that even if the patient has no deemed symptoms, he/she may be tested positive (Hoehl et al., 2020). The obscurity of the spreading level caused the precautions of the countries to become more compelling. Countries try to slow down the spread by imposing restrictions like cancelling sport crowded gatherings such as events, concerts, exhibitions, closing bars and restaurants, limiting travels, cancelling transportation, quarantining citizens. The crisis of health caused by the pandemic also results in the crisis in economy, mass psychology, communication and politics. The understanding of the norm and culture is changing irreversibly.

Because of the uncertainty of the process, conspiracies and misinformation come into prominence. During the quarantine times, the main resource of the information flow has become the Internet which made social media a mass communication device where mainstream and alternative news agencies choose to spread their news regarding COVID-19. Considering the significance of the media coverage and people trying to be up to date about the latest news, social media such as Twitter and Facebook have turned into being the main sources of information (Llewellyn, 2020). It is clear that the misinformation, fake news or the way of breaking news has a huge impact on the public and policy makers. Thus, deliberate usage of the news media by the media professionals and public health authorities is crucial (Depoux et al., 2020). Scholars suggest that govern- 
ments, public health authorities and media agencies should work together to avoid psychological crises such as mass panic which may arise by the misinformation and the fake news spreading through social media by daily briefing and openly sharing the daily outcomes of the disease using data visuals or detailed maps (Hopman, Allegranzi, and Mehtar, 2020). These data graphics and visuals shared by media organizations have an undeniable influence on the public, thus, the choices made by the media agencies and the health officials are potent.

\section{RISK COMMUNICATION}

In a broader sense, risk is defined as the lack of certainty. The immense advance in technology, ongoing globalization, unstable environmental issues and many other social, economic and cultural factors increase the uncertainty and risk elements in all aspects of life. Since risk has become the unavoidable part of life, developing strategies to manage risk is inevitable. Risk communication is the primary strategy to manage uncertainty and crisis. It is also stated that risk communication functions as the preventive measure for crisis (Sellnow et al., 2008). The National Research Council (1989: 21) describes risk communication as:

An interactive process of exchange of information and opinion among individuals, groups, and institutions. It involves multiple messages about the nature of risk and other messages, not strictly about risk, that express concerns, opinions, or reactions to risk messages or legal or institutional arrangement of risk management.

According to Sellnow et al. (2008) the definition highlights two important details of risk communication. First of all, risk communication is an interactive process, in which different stakeholders send and receive messages. Another key point is risk communication includes multiple content messages. Hence, the content of the messages should be customized by considering different needs, values, background, culture and experience of each stakeholder group (Sampson et al., 2001); otherwise non-experts or unqualified people interpret risk information irrationally and inaccurately, which may result in concerns and lack of trust among citizens (Covello et al., 2001). In other words, credibility is important for believability and effectiveness of the message. To enhance credibility, risk messages should include simple and clear statements; further, they should be reasonable and emotionally appealing (Reynolds and Seeger, 2005). Briefly, with the correct coding of the risk messages, the risk communication process can be effective.

Another variable that impacts risk communication is the emotional state of the receiver. During any type of health crises, strong negative emotions such as fear, anxiety, distrust may become obstacles that destroy accuracy of the communication message (Guidry et al., 2020). Since common understanding of risk in public does not always match with the scientific truth, the main focus of risk communication is investigating the rationale of risk (Reynolds and Seeger, 2005). 


\section{RISK PERCEPTION AS A RISK COMMUNICATION MODEL}

In theory, risk communication is grounded in four models; risk perception, mental noise, negative dominance and trust determination. The four models together aim to explain how risk information is processed, how risk perceptions are formed, and how risk decisions are made. It is claimed that these models establish substantial elements of effective communication, which should be applied in high-concern cases (Covello et al., 2001). The mental noise model mentions that the ability to process risk information decreases under stressful conditions. Negative dominance model suggests that individuals recognize losses or negative content under stress rather than positive information. On the other hand, the trust determination model points out that people show a tendency of distrust when they are under stress (Cairns, Andrade, and MacDonald, 2013).

The risk perception model addresses how risks are perceived. The model points that many factors influence risk perception, and the degree of risk perception can change in relation to these factors. Although 15 factors that influence risk perception have been identified (Covello et al., 2001), Guidry et al. (2020), categorize risk perception factors into three; (a) risks that evoke fear, terror, or anxiety (b) risks associated with institutions or organizations that are lacking in credibility and trust; and (c) risks that produce fatalities or have irreversible, catastrophic consequences.

The media's influence on risk perception has been studied by risk, communication and media researchers. Some of the studies state that the media give biased information and exaggerate some risks while underestimating more serious ones. However, some illustrate that the media is a strong channel for governmental agencies and organizations to inform the public about the risk content and to change their behaviours or attitudes. Moreover, personal factors may affect the risk perception process. Personal risk perception process may be different from the general risk perception process; therefore, making rigid conclusions is not possible (Wahlberg and Sjoberg, 2000). On the other hand, Vilella-Vila and Costa-Font (2008) state that receivers' attitudes towards journalists also determine their risk perception in relation to the media coverage. They support the claim there is media bias in newly created technology news. Park and Sohn (2013) also mentioned that for a stronger and more influential risk communication the consistency and objectivity of news content are necessary. Additionally, unity between media content and governmental bodies' and experts' content is vital. In order to build this collaborative environment, open communication should be employed.

The immense use of data visualization to transmit messages during risk communication is another topic that is subject to debate. Well-known newspapers, The New York Times and The Guardian are two vivid examples that have popularized data visuals to convey strong messages. Nevertheless, the influence of data visualization is not certain (Pandey et al., 2014). Especially, the effects of data visuals on risk perception is a topic, which has not been clarified yet. Therefore, it is important to reveal how members of the public perceive data visuals of COVID-19 shared by the media in the context of risk perception. 


\section{DATA VISUALISATION IN MEDIA DURING RISK} COMMUNICATION

Graphical representation of scientific information is known as infographics (Lankow, Ritchie, and Crooks, 2012; Smiciklas, 2012). Visually presenting a data set is an effective way of delivering scientific information due to space limitations and the public tends to understand visuals more easily in comparison with written materials (Dur et al., 2014; Shin, 2016). According to research studies, visual stimuli have a positive impact on people in terms of grasping the main idea of a content via spending less time thinking about it (Siricharoen, 2013). Especially, in times of crises using visuals to convey scientific data to the public becoming more common in media. Journalists prefer to tell their health and risk-related stories with the help of visualized statistical data. In a research, Bell et al. (2006) determined that the audience finds the statistical data to be more trustworthy rather than other types of information regarding health and risk issues. Previous research also suggested that images have a significant role in shaping the public's interpretation of an issue (Gibson and Zillman, 2000; Zillman, Gibson, and Sargent, 1999). That is the reason, recently scholars are getting interested to examine visuals in media coverage, however, they usually focus on photographs. Therefore, investigating the effect of data visuals on public's perception would contribute to the risk communication studies. As explained in the introduction, the impact of COVID-19 pandemic on societies is also still unfolding. Therefore, examining the factors that might have any effect on the public's risk perception during a pandemic would also be a contribution.

\section{METHODOLOGY}

\section{RESEARCH DESIGN}

In order to investigate the risk perception of the public regarding data visuals of news reports on COVID-19 pandemic, we used a quantitative survey design. Quantitative research design enables researchers to answer the questions of who, what, when, where, and how in relation to the research problem (Given, 2007). In communication sciences quantitative research is frequently used to understand how patterns of behaviours or perceptions might vary from one group of people to another. Additionally, in survey designs, researchers can collect answers for a set of questions to draw conclusions. The strongest quality of survey design is reaching large random samples in a short time and appearing in a more naturalistic environment; therefore, making stronger generalizations is possible (Allen, Titsworth, and Hunt, 2008). For all these reasons, to answer the research question below, we conducted an online survey.

RQ: How do participants perceive data visuals of COVID-19 shared on Facebook and Twitter by the media in the realm of the three main constructs of Risk Perception Model? 


\section{The SAmple}

We used the snowball sampling method, and we reached out to respondents via social media and the internet. The snowball sampling is preferred when the target audience is not easily accessible, marginal and the questions are personal (Noy, 2008). Since during COVID-19 pandemic, conducting face to face research is not possible, snowball sampling is the most efficient way of collecting data. Moreover, because the study explores perceptions of individuals on a very personal topic, snowball sampling is very convenient for the purpose of our research.

The sample consists of 191 adults in total. The demographics of the participants were determined at the end of the survey. The sample consisted of highly educated urban-based individuals who held degrees such as master's or higher $(n=101,52.9$ percent) and university level education $(n=80,41.9$ percent). In total, our sample mostly consisted of individuals with complete university level education ( $\mathrm{n}=181,94.8$ percent). Thus, the highest education level attained is considerably higher than average Turkish citizen. ${ }^{1}$ In addition, the respondents tend to place themselves towards the left of the political spectrum and; thus, they are more left leaning than the average Turkish citizen. ${ }^{2}$ The participants also stated that they are highly interested in news and majority of them follow the media on a daily basis, and spend at least 30 minutes or more to read news $(n=155$, 81.1 percent). The news sources they prefer for COVID-19 news coverage are mainly online news websites, social media accounts of news outlets, WhatsApp groups and television. Here we must note that the internet penetration in Turkey is 68 percent as of 2019 (Newman et al., 2019). Especially online news and social media are widely used for alternative and critical perspectives amongst urban-based individuals (Newman et al., 2019). Therefore, the above-mentioned characteristics of our sample were expected as we mainly sampled through social media. On the other hand, the respondents are well proportioned in terms of age span (between 18 and 75) and working conditions (private sector, public sector, owns business, retired, non-working, student, unemployed). The majority of the participants were women ( $n=126,66$ percent). Lastly, while the majority of the participants stated that they had no symptoms of COVID-19 so far ( $n=161,84.3$ percent), in their close circle (family, friends and at work) they have people who were infected with the virus $(n=55,28.8$ percent).

1 According to the WVS, the highest ration in the highest education level attained in Turkey is "complete primary school degree" ( $n=481[1605$ total], 30 percent). The university graduates are 11.1 percent of the entire sample with 178 cases ("World...", n.d.).

2 In the WVS, the mean is 6.39 on a scale that ranges between 1 (left) and 10 (right) ("World...", n.d.). 


\section{Data Collection Method}

We used a 5-point Likert type scale which allows respondents to express how much they agree or disagree for the given statements about 24 data visuals of COVID-19 news report. The chosen visuals appeared on media were mainly provided by the state departments, as well as international organizations such as WHO (World Health Organization). Our selection criteria was their interaction level on social media as we recruited our participants through social media. Therefore, amongst our participants, the widespread impact of the images that attracted the most attention would be higher. Thus, we firstly determined the social media accounts of the five most popular news outlets according to their follower numbers on Twitter and Facebook. Three of them overlapped appearing in the top five of both social media, therefore, the top five in both social media consisted of the following seven news outlets: BBC Turkish (Twitter: 3.6M, Facebook: 1.4M); Habertürk (Twitter: 4.3M, Facebook: 2.2); TRT Haber (Twitter: 3.4M, Facebook: 3.2M); Hürriyet (Twitter: 3.3M, Facebook: 2.9M); CNN Türk (Twitter: 5.1M, Facebook: 1.7M); Sabah (Twitter: 2M, Facebook: 3.1M); Sözcü (Twitter: 2.4M, Facebook: 3M). Then, we chose the most shared and liked data visuals of COVID-19 related news reports from these sources. The selected data visuals consisted of the current situation graphics in Turkey, and in the world, graphics of increase and decrease in the cases, most affected cities, map of the distribution of the cases in big cities and Turkey, top five countries in confirmed cases, current situation in the top 10 infected countries, infographics regarding the importance of isolation, infographic pie chart about the decreasing social mobility, scatter plot chart of daily cases of death in Turkey, column chart of distribution of death rate by age and sex etc. The chosen visuals are shared between March 11, 2020 (the first officially approved COVID-19 case announced in Turkey) and April 21, 2020 (the survey development process was completed) on the official social media accounts of the selected news outlets.

As for the statements used in the scale, each has a numerical value ranging from 1 -strongly disagree- to 5 - strongly agree - to measure the risk perception. We categorized these statements into three groups adopting from Guidry et al. (2020), who tailored the risk perception model of Covello et al. (2001) to social media. First part was about the level of anxiety, fear and panic arousal of the participants. Second part was about the level of lacking credibility and trust. The third and the last part was about the impression of fatality, irreversible effects and catastrophic consequences. In total, we created eight items in three categories. In the survey, we ask respondents to score 8 items for each data visual.

\section{FINDINGS}

We conducted a descriptive analysis and used frequency, standard deviation and mean scores to analyse the data. To measure the risk perception score of the respondents for each data visual (out of 24), we apply the following formula for all 8 statements of risk perception. In a 5-point Likert type scale, of which range is $4(5-1=4)$, the greatest value of the scale, 5 , is divided into $4(4 / 5=0.80)$, and the 
144 range values are determined as; between 1 and 1.80 represents strongly disagree, between 1.81 and 2.60 represents do not agree, between 2.61 and 3.40 represents neutral, between 3.41 and 4.20 represents agree, between 4.21 and 5.00 represents strongly agree.

Figure 1. Visual 7: Number of laboratory approved cases, death and recovery (TRT News)

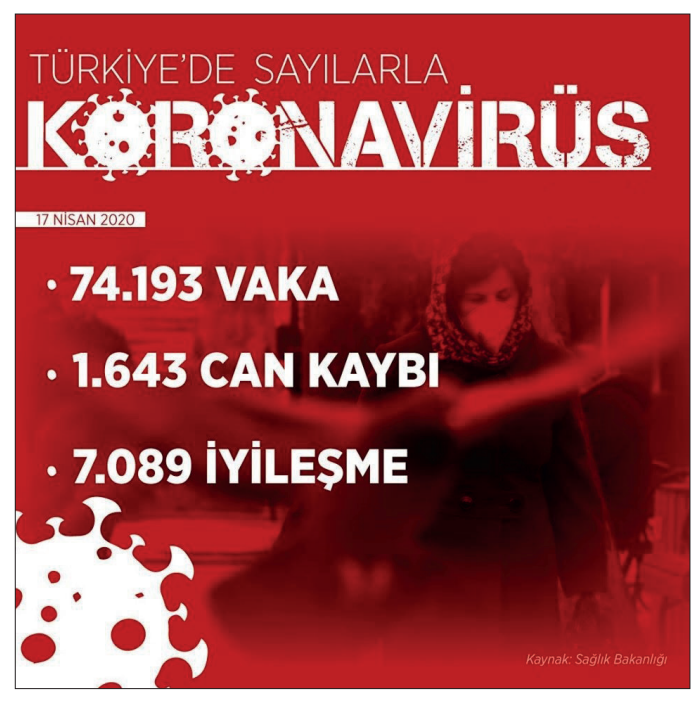

Source: Ministry of Health.

Figure 2. Visual 21: The number of death in Turkey (BBC Turkish)

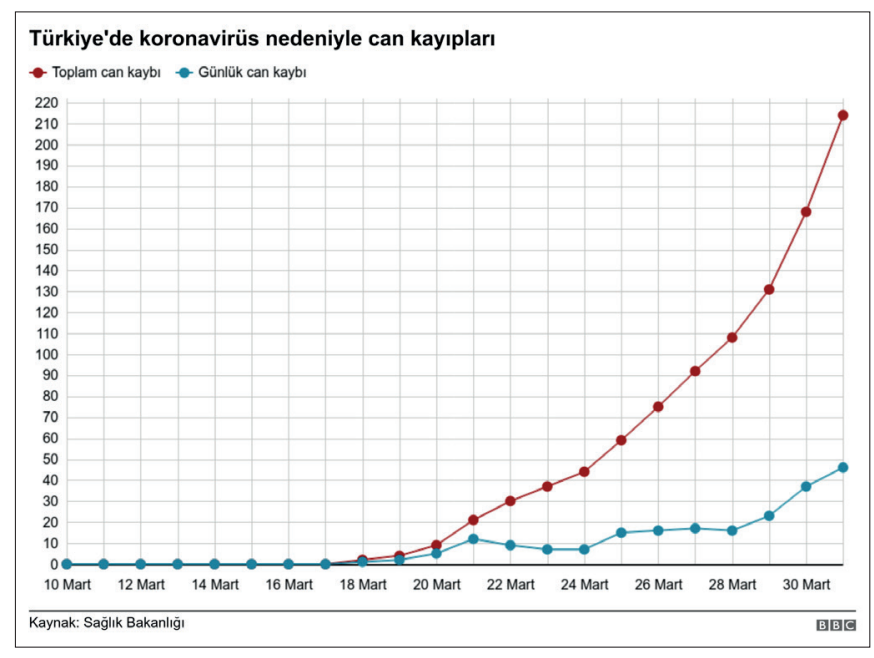

Source: Ministry of Health. 
Figure 3. Visual 23: Scatter Plot of Increasing Laboratory Approved Cases in 10 days of 4 countries (Turkey, Iran, Italy, England) (BBC Turkish)

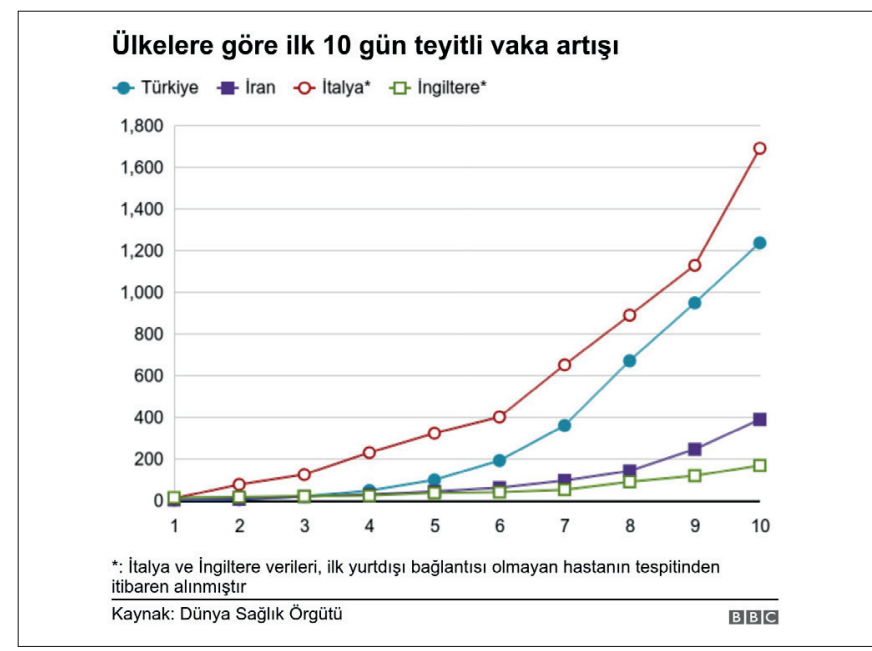

Source: World Health Organization.

The results of the study illustrate that respondents' risk perception mean scores for data visuals 7 (3.42), 21 (3.61) and 23 (3.44) are over 3.41, which means the respondents agree that the visuals depict risk elements.

\section{Figure 4}

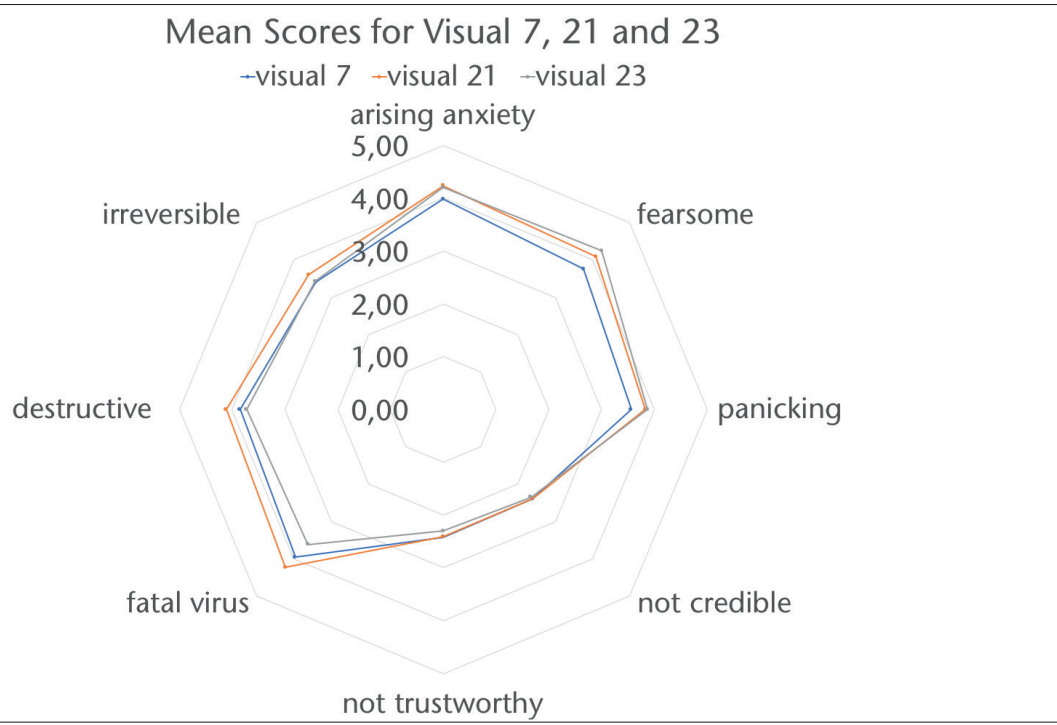

Source: Own elaboration. 
146 When analyzed the mean scores of the items for the data visual 21, it is seen that item 1 (the data visual arousing anxiety) (4.24) and item 6 (the data visual shows that the virus is fatal) (4.23) has the mean scores over 4.21 , which means participants strongly agree with the statements.

For the data visual 23, item 1 (the data visual arousing anxiety), 2 (the data visual is fearsome), 3 (the data visual is panicking), 6 (the data visual shows that the virus is fatal), 7 (the data visual shows that the virus has destructive effects), 8 (the data visual shows that the virus has irreversible consequences) has mean scores over 3.41. This reveals that participants agree with these statements.

Likewise, for the data visual 7, item 1 (the data visual arousing anxiety), 2 (the data visual is fearsome), 3 (the data visual is panicking), 6 (the data visual shows that the virus is fatal), 7 (the data visual shows that the virus has destructive effects), 8 (the data visual shows that the virus has irreversible consequences) has mean scores over 3.41. This reveals that participants agree with these statements. 


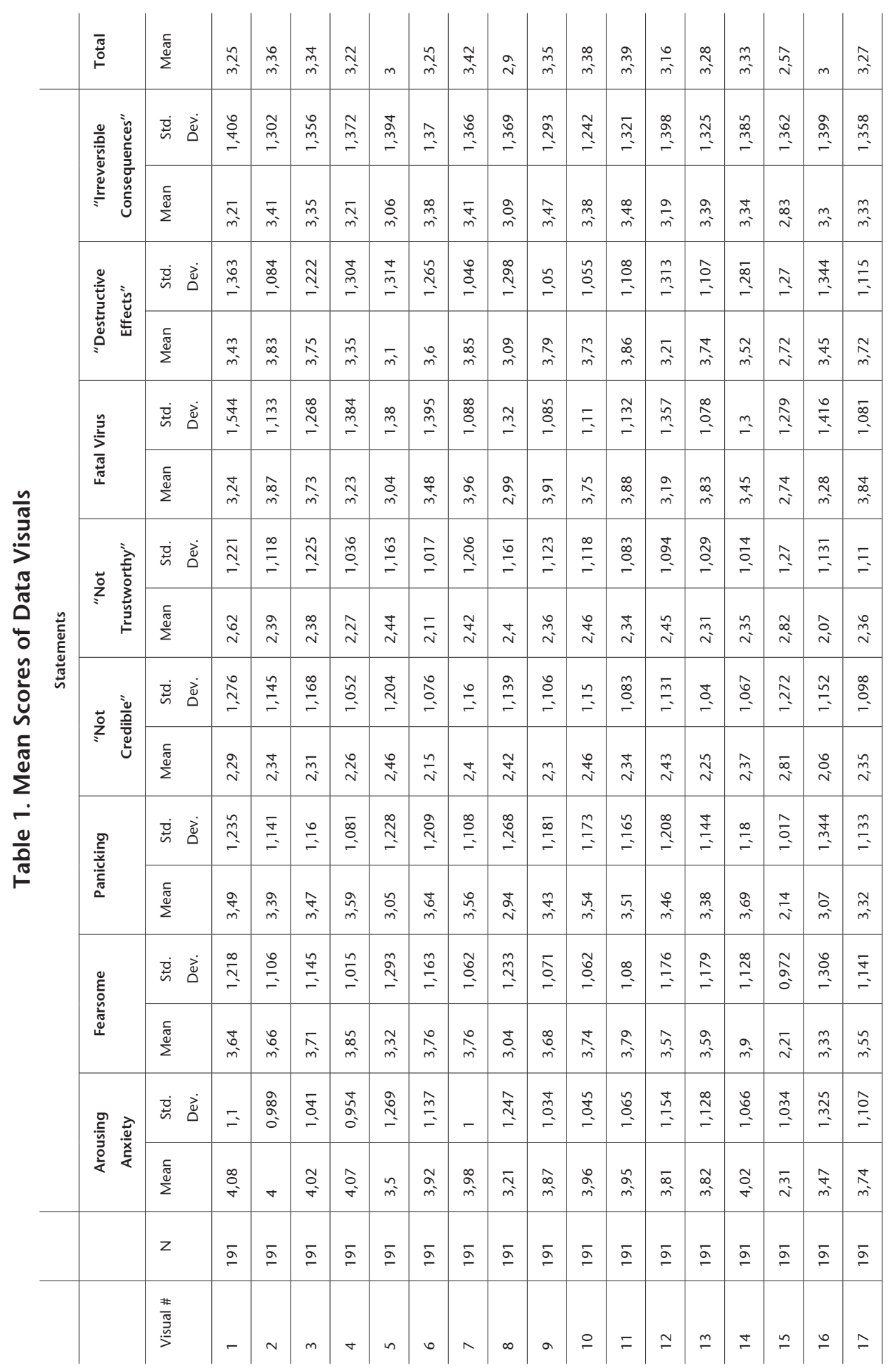




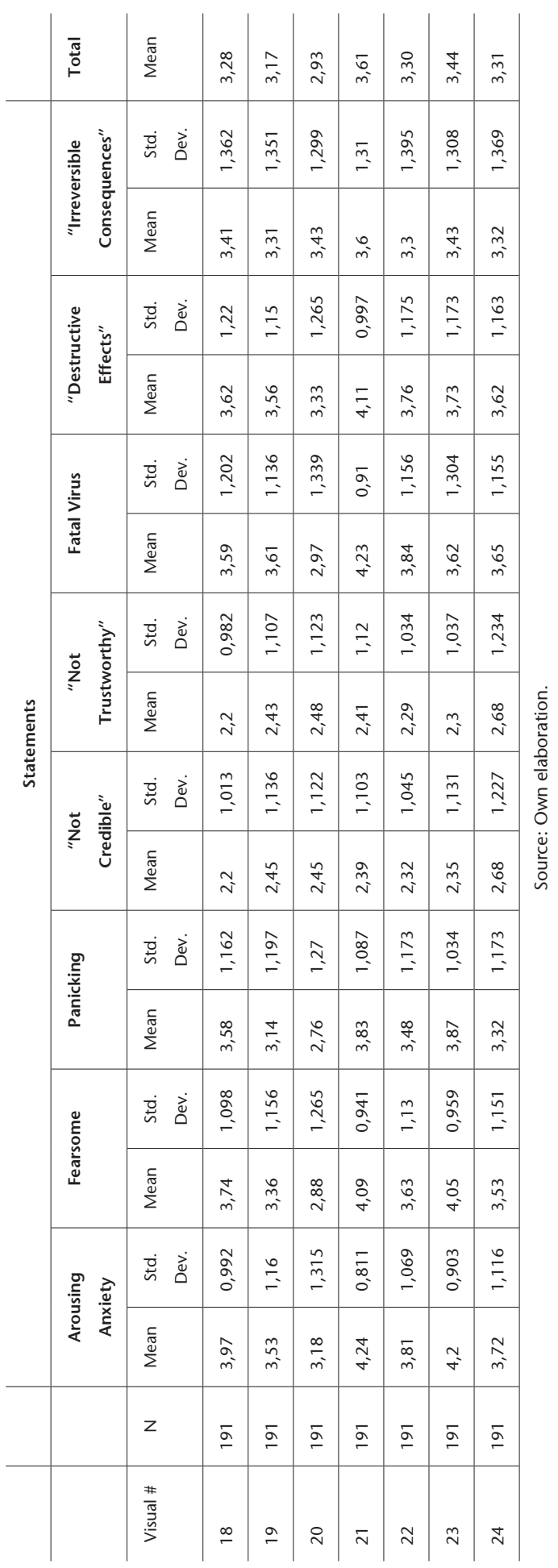


As shown in Table 1, for all 24 data visuals, it is vivid that mean scores for item 1 (the data visual arousing anxiety) is over 3.41, which is the threshold for "agree", except for the data visuals 8, 15 and 20. For item 2 (the data visual is fearsome), the majority of the data visuals' mean score is over 3.41, except for data visuals 5, $8,15,16,19,20$. The result shows that respondents agree that the visuals are fearsome. For item 3 (the data visual is panicking), 14 data visuals out of 24 , which are $1,3,4,6,7,9,10,11,12,14,18,21,22,23$ are over 3.41 , which means that participants perceive the visuals as panicking.

It is also noticeable that for item 4 (the data on the visuals are not credible) and 5 (the data on the visuals are not trustworthy) the mean scores are below 3.41. It reveals that participants perceive the data as credible and trustworthy. The sources of the data visuals were the state institutions and international organizations, and were indicated on the visuals clearly. Therefore, we assume that risk perception associated with organizations and institutions is low for the sample of the research. Another distinctive result of the research is that for item 8 (the data visual shows that the virus has irreversible consequences), a minority of the data visuals $(2,3,7,10,11,18,20,21,23)$ has a mean score above 3.41 . This reveals that our respondents do not perceive the virus as a risk in relation to irreversible consequences presented on the specified visuals.

\section{CONCLUSION}

The goal of this research was to investigate the role that data visuals in media coverage play on the risk perception of the public during COVID-19 pandemic in Turkey. Utilizing data from an online survey of 191 participants within the framework of the risk perception model, we first divided eight statements into three groups as indicators of the risk perception. Then, we selected 24 data visuals that attracted the most interaction from the seven most popular news outlets on Facebook and Twitter.

The study uncovered that the participants perceive several risk elements on data visuals of COVID-19, and they do not question the credibility and reliability of the data presented in visuals, the source of which were the state institutions and international organizations. This highlights that respondents' risk perception will be less associated with institutions or organizations as stated in the recent research (Guidry et al., 2020). We believe that since the source of the data is mainly provided by the World Health Organization and the Ministry of Health, which are the superior authorities for managing the flow of the data and information during COVID-19, the rate of credibility and reliability of the visuals were high. Likewise, Covello et al. (2001) mention that experts and qualified people are accepted as credible sources. Also, Reynolds and Seeger (2005) states that brief, simple and clear content is frequently received as reliable as it happens in our data visuals. In these respects the results of our research is consistent with the prior literature. The results of the study also show that when the visuals represent the increased rate of the virus rather than the approved cases or the number of deaths, the risk perception is lower. We think that statistics underline the ill and 
dead people lead to anxiety and fear, which resulted in higher risk perception as the previous research already revealed (Covello et al., 2001).

Another distinctive point worth investigating is that risk perception for different sexes. In COVID-19 media reports, it was usually stressed that according to sex-specific records, proportion of men was higher than women regarding deaths from COVID-19 (e.g. Ball, 2020). Here we must note that the majority of our sample consisted of women ( $n=126,66$ percent), therefore, sex could be an intervening factor and this could be amongst one of the explanations why the overall risk perception was not high in many cases in our sample.

Finally, respondents of the study mostly do not agree that the virus has irreversible consequences when looking at the data visuals even though they believe the visuals reflect fear, panic and anxiety. It may imply that participants think the virus as a temporary threat.

The study is limited in terms of its sample size of 191 respondents and their characteristics, as well as, its specific timing when the COVID-19 was climactic for Turkey. Therefore, the results are bound to a certain time, environment, and people, and thus, the findings of the study just have initial implications for exploring the agents that might have any effect on the public's risk perception during an unfolding pandemic. Future research should further examine a larger and a representative sample on different time periods, and explore whether sex, different education levels, political views or other socioeconomic agents, as well as, news following patterns and ever being infected with the virus have an intervening effect in terms of the risk perception of the public during a pandemic.

Dilek Melike Uluçay (melike.taner@yasar. edu.tr), PhD. After completing her undergraduate studies at Faculty of Letters in English Language and Literature Department at Hacettepe University (2003), Dilek Melike Uluçay completed her PhD degree at Anadolu University in the major field of Communication De-

Gizem Melek (gizem.melek@yasar.edu. tr), PhD, is an Assistant Professor at the Department of Radio, Television \& Cinema, Yaşar University. Her main academic research areas include media effects, agenda-setting and political communication. In addition to her aca- sign and Management (2012). She is currently working at Yaşar University as an assistant professor at the Faculty of Communication in the Department of Public Relations and Advertising. Her research interests are corporate communication, consumer behaviour, marketing communications and new media.

demic work, she is an experienced journalist who worked both in Turkey and in the UK for six years. The places she worked include Izmir Life news magazine, NTV-nationwide Turkish news network, ITV-British TV network and the British Museum's Broadcast Unit. 
Deniz Özyurda-Ergen (deniz.ergen@yasar. edu.tr) is a Research Assistant in Yaşar University at the Department of New Media and Communication. She received her BA from the Bilkent University, Dept. of Communication and Design. She is continuing her education as a master's student in Ankara University, Communication Faculty, Radio, Television and Cinema Department. She is in the writing process of her thesis "An Ethnography of Games: Gender Perception of Male Player Communities Who Prefers to Play Female Characters" in which she researches the relationship between gender and male player perspective of female game characters. Her research interests are film, gender and digital games.

\section{References}

Allen, M.; Titsworth, S., and Hunt, S. K. (2008). Quantitative Research in Communication. Thousand Oaks, CA: Sage Publications.

Al-Rabiaah A.; Temsah, M. H.; Al-Eyadhy, A.; A. Hasan, G. M.; Al-Zamil, F.; Al-Subaie, S.; Alsohime, F.; Jamal, A.; Alhaboob, A.; Al-Saadi, B., and Somily, A. M. (2020). "Middle East Respiratory Syndrome-CoronaVirus (MERS-CoV) Associated Stress Among Medical Students at a University Teaching Hospital in Saudi Arabia". Journal of Infection and Public Health, in press. DOI: <https://doi.org/10.1016/j. jiph.2020.01.005>.

Angeli, E. L. (2012). "Metaphors in the Rhetoric of Pandemic Flu: Electronic Media Coverage of H1N1 and Swine Flu". Journal of Technical Writing and Communication, 42(3), pp. 203-222. DOI: <https://doi.org/10.2190/ TW.42.3.b>.

Ball, P. (2020). "Coronavirus Hits Men Harder. Here's What Scientists Know about It". The Guardian. Available at: <https://bit. ly/3d1IuVV>. Accessed 30 April 2020.

Bell, B. S.; Hoskins, R. E.; Pickle, L. W., and Wartenberg, D. (2006). "Current Practices in Spatial Analysis of Cancer Data: Mapping Health Statistics to Inform Policymakers and the Public". International Journal of Health Geographics, 5(1), pp. 49. DOI: <https://doi. org/10.1186/1476-072X-5-49>.

Cairns, G.; Andrade, M., and MacDonald, L. (2013). "Reputation, Relationships,
Risk Communication, and the Role of Trust in the Prevention and Control of Communicable Disease: A Review". Journal of Health Communication, 18(12), pp. 1550-1565. DOI: $<10.1080 / 10810730.2013 .840696>$.

Centers for Disease Control and Prevention. (2020). "How COVID-19 Spreads". Available at: <https://bit.ly/2SfnUcO>. Accessed 26 April 2020.

Chew, C. and Eysenbach, G. (2010). "Pandemics in the Age of Twitter: Content Analysis of Tweets During the 2009 H1N1 Outbreak". PloS one, 5(11), pp.1-15.

Coronavirus Disease 2019 (COVID-19) Situation Report - 99. (2020). World Health Organization. Available at: <https://bit. ly/2YiPsSC $>$. Accessed 29 April 2020.

Countries Where COVID-19 Has Spread. (2020). Available at: <https://bit.ly/2yahl4i>. Accessed 26 April 2020.

Covello, V. T.; Peters, R. G.; Wojtecki, J. G., and Hyde, R. C. (2001). "Risk Communication, the West Nile Virus Epidemic, and Bioterrorism: Responding to the Communication Challenges Posed by the Intentional or Unintentional Release of a Pathogen in an Urban Setting". Journal of Urban Health, 78(2), pp. 382-391.

Depoux, A.; Martin, S.; Karafillakis, E.; Preet, R.; Wilder-Smith, A., and Larson, H. (2020). "The Pandemic of Social Media Panic Travels Faster than the COVID-19 Outbreak". 
Journal of Travel Medicine. DOI: $<10.1093 / \mathrm{jtm} /$ taaa031/5775501>.

DeSteno, D. (2020). "How Fear Distorts Our Thinking about the Coronavirus". The New York Times. Available at: <https://nyti. ms/2W4swn7>. Accessed 26 April 2020.

Dur, B. I. U.; Filipczak-Bialkowska, A.; Bresciani, S.; Ge, J.; Niu, Y.; Othman, A., and Wils, D. (2014). "Interactive Infographics on the Internet". In the International Conference on Communication, Media, Technology and Design, Department of Visual Communication Design, TOBB University of Economics and Technology.

Falagas, M. E. and Kiriaze, I. J. (2006). "Reaction to the Threat of Influenza Pandemic: The Mass Media and the Public". Crit Care, 10(2). DOI: <https://doi.org/10.1186/cc4910>.

Gibson, R. and Zillman, D. (2000). "Reading Between the Photographs: The Influence of Incidental Pictorial Information on Issue Perception". Journalism \& Mass Communication Quarterly, 77(2), pp. 355-366.

Given, L. M. (2007). "Descriptive Research". In: Neil, J. S. and Rasmussen, K. (ed.). Encyclopedia of Measurement and Statistics. Thousand Oaks, CA: Sage, pp. 251-254.

Guidry, J. P.; Meganck, S. L.; Perrin, P. B.; Messner, M.; Lovari, A., and Carlyle, K. E. (2020). "\#Ebola: Tweeting and Pinning an Epidemic". Atlantic Journal of Communication. DOI: <10.1080/15456870.2019.1707202>.

Hoehl, S.; Rabenau, H.; Berger, A.; Kortenbusch, M.; Cinatl, J.; Bojkova, D.; Behrens, P.; Böddinghaus, B.; Götsch, U.; Naujoks, F.; Neumann, P.; Schork, J.; TiarksJungk, P.; Walczok, A.; Eickmann, M.; Vehreschild, M.; Kann, G.; Wolf, T.; Gottschalk, R., and Ciesek, S. (2020). "Evidence of SARS-CoV-2 Infection in Returning Travelers from Wuhan, China". N Engl J Med. DOI: $<10.1056 /$ NEJMc2001899 $>$.

Hopman J.; Allegranzi B., and Mehtar S. (2020). "Managing COVID-19 in Low —and Middle- Income Countries". JAMA. DOI: $<10.1001 /$ jama.2020.4169>.
Huang, P. H. (2020). "Lessening Anxiety, Panic, and Complacency in Pandemics". $U$ of Colorado Law Legal Studies Research Paper, 20-14. DOI: <http://dx.doi.org/10.2139/ ssrn.3575101>.

Lampos, V. and Cristianini, N. (2010). "Tracking the Flu Pandemic by Monitoring the Social Web". Presented at the 2nd International Workshop on Cognitive Information Processing. Italy, 14-16 June.

Lankow, J.; Ritchie, J., and Crooks, R. (2012). Infographics: The Power of Visual Storytelling. Hoboken, NJ: John Wiley.

Llewellyn, S. (2020). "COVID-19: How To Be Careful with Trust and Expertise On Social Media". BMJ. DOI: <10.1136/bmj.m1160>.

Lopes, F.; Ruão, T.; Marinho, S., and Araújo, R. (2012). “A Media Pandemic: Influenza A in Portuguese Newspapers". International Journal of Healthcare Management, 5(1), pp. 19-27. DOI: <10.1179/2047971911y.0000000001>.

Morens, D. M.; Folkers, G. K., and Fauci, A. S. (2009). "What Is a Pandemic?". The Journal of Infectious Diseases, 200(7), pp. 1018-1021. DOI: <https://doi.org/10.1086/644537>.

National Research Council. (1989). Improving Risk Communication. Washington, DC: National Academy Press.

Newman, N.; Fletcher, R.; Kalogeropoulos, A., and Nielsen, R. K. (2019). "Digital News Report 2019". Reuters Institute. Available at: $<$ https://bit.ly/2yMLNBu>. Accessed 26 April 2020.

Noy, C. (2008). "Sampling Knowledge: The Hermeneutics of Snowball Sampling in Qualitative Research". International Journal of Social Research Methodology, 11(4), pp. 327344. DOI: <10.1080/13645570701401305>.

Pandey, A. V.; Manivannan, A.; Nov, O.; Satterthwaite, M., and Bertini, E. (2014). "The Persuasive Power of Data Visualization". IEEE Transactions on Visualization and Computer Graphics, 20(12), pp. 2211-2220.

Park, J. E. and Sohn, A. (2013). "The Influence of Media Communication On Risk Perception and Behavior Related to Mad Cow 
Disease in South Korea". Osong Public Health and Research Perspectives, 4(4), pp. 203-208. DOI: <10.1016/j.phrp.2013.06.005>.

Reynolds, B. and Seeger, M. W. (2005). "Crisis and Emergency Risk Communication As an Integrative Model". Journal of Health Communication, 10(1), pp. 43-55. DOI: $<10.1080 / 10810730590904571>$.

Sampson, K. W.; Morrison K.; Wen-Ying L.; Hubbell A. P., and Murray-Johnson, J. L. (2001). "Addressing Cultural Orientations in Fear Appeals: Promoting AIDS-Protective Behaviors among Mexican Immigrant and African American Adolescents and American and Taiwanese College Students". Journal of Health Communication, 6(4), pp. 335-358.

Sellnow, T. L.; Ulmer, R. R.; Seeger, M. W., and Littlefield, R. (2008). Effective Risk Communication: A Message-Centered Approach. New York: Springer Science \& Business Media.

Shin, H. (2016). "Epidemic and Risk Communication: An Analysis of Strategic and Graphic Characteristics of Infographics". Graduate Theses and Dissertations. 15172. <https:// lib.dr.iastate.edu/etd/15172>.

Siricharoen, W. V. (2013). "Infographics: The New Communication Tools in Digital Age". Presented at the International Conference on E-Technologies and Business on the Web (EBW2013). Bangkok, 7-9 May.

Smiciklas, M. (2012). The Power of Infographics: Using Pictures to Communicate and Connect with Your Audiences. Indianapolis, In: Que Publishing.
Szomszor, M.; Kostkova, P., and Louis, C. S. (2011). "Twitter Informatics: Tracking and Understanding Public Reaction During the 2009 Swine Flu Pandemic". Presented at IEEE/ WIC/ACM International Conferences on Web Intelligence and Intelligent Agent Technology. Lyon, 22-27 August.

Türkiye'deki Güncel Durum [Current Situation in Turkey]. (2020). TC. Sağlik Bakanlığı. Available at: <https://covid19. saglik.gov.tr/>. Accessed 29 April 2020.

Vilella-Vila, M. and Costa-Font, J. (2008). "Press Media Reporting Effects on Risk Perceptions and Attitudes Towards Genetically Modified (GM) Food". The Journal of Socio-Economics, 37(5), pp. 2095-2106. DOI: <10.1016/j. socec.2008.04.006>.

Wahlberg A. and Sjoberg, L. (2000). "Risk Perception and the Media". Journal of Risk Research, 3(1), pp. 31-50. DOI: $<10.1080 / 136698700376699>$.

World Health Organization. (2010). "What is a Pandemic?". Available at: <https:// bit.ly/2y9aI2d>. Accessed 26 April 2020.

—. (2020). "Coronavirus Disease (COVID-19) Situation Dashboard". Available at: <https:// covid19.who.int/>. Accessed 28 April 2020.

World Values Survey. (n.d). "World Values Survey Wave 6: 2010-2014”. Available at: <http://www.worldvaluessurvey.org/WVS Online.jsp>. Accessed 26 April 2020.

Zillman, D.; Gibson, R., and Sargent, S. L. (1999). "Effects of Photographs in NewsMagazine Reports on Issue Perception". Media Psychology, 1(3), pp. 207-228. 
